\title{
Doubly-Amphiphilic Poly(2-oxazoline)s as High-Capacity Delivery Systems for Hydrophobic Drugs
}

\author{
Robert Luxenhofer ${ }^{1,2, \ddagger}$, Anita Schulz ${ }^{1,2, \ddagger}$, Caroline Roques ${ }^{1}$, Shu Li ${ }^{1}$, Tatiana K. Bronich ${ }^{1}$, \\ Elena V. Batrakova ${ }^{1}$, Rainer Jordan $2, \ddagger$, and Alexander V. Kabanov ${ }^{1}$ \\ ${ }^{1}$ Department of Pharmaceutical Sciences and Center for Drug Delivery and Nanomedicine, College \\ of Pharmacy, University of Nebraska Medical Center, 985830 Nebraska Medical Center, Omaha, \\ NE, 68198-5830 (United States), akabanov@unmc.edu, Phone: +01-402-559-9364, Fax: + \\ 01-402-559-9365
}

${ }^{2}$ Wacker-Lehrstuhl für Makromolekulare Chemie, Department Chemie, Technische Universität München, Lichtenbergstr. 4, 85747 Garching (Germany), robert.luxenhofer@chemie.tudresden.de, Phone: +46-351-463-36057, Fax: +49-351-463-37122

\begin{abstract}
Solubilization of highly hydrophobic drugs with carriers that are non-toxic, non-immunogenic and well-defined remains a major obstacle in pharmaceutical sciences. Well defined amphiphilic di- and triblock copolymers based on poly(2-oxazolines) were prepared and used for the solubilization of Paclitaxel (PTX) and other water-insoluble drugs. Probing the polymer micelles in water with the fluorescence probe pyrene, an unusual high polar microenvironment of the probe was observed. This coincides with an extraordinary large loading capacity for PTX of $45 \mathrm{wt} . \%$ active drug in the formulation as well as high water solubility of the resulting formulation. Physicochemical properties of the formulations, ease of preparation and stability upon lyophilization, low toxicity and immunogenicity suggest that poly(2-oxazoline)s are promising candidates for the delivery of highly challenging drugs. Furthermore, we demonstrate that PTX is fully active and provides superior tumor inhibition as compared to the commercial micellar formulation.
\end{abstract}

\section{Keywords}

drug delivery; solvatochromism; polymer micelles; polyoxazolines; polymerization

(C) 2009 Elsevier Ltd. All rights reserved.

Correspondence to: Robert Luxenhofer; Alexander V. Kabanov.

*Current address: Professur für Makromolekulare Chemie, Department Chemie, Technische Universität Dresden, Zellescher Weg 19 , 01069 Dresden (Germany)

Supplementary Information Available: Pyrene fluorescence spectra in aqueous solutions of different amphiphilic block copolymers and the ionic liquid 1-butyl-2,3-dimethylimidazolinium chloride ([bdmim]/[Cl] $)$. Dynamic light scattering data of drug loaded micelles. Graphs of cytotoxicity of plain polymers in various cell lines. Table of values of $\mathrm{I}_{1} / \mathrm{I}_{3}$ ratios in a variety of polymer solutions, solvents and ionic liquids as illustrated in Fig. 1

Publisher's Disclaimer: This is a PDF file of an unedited manuscript that has been accepted for publication. As a service to our customers we are providing this early version of the manuscript. The manuscript will undergo copyediting, typesetting, and review of the resulting proof before it is published in its final citable form. Please note that during the production process errors may be discovered which could affect the content, and all legal disclaimers that apply to the journal pertain. 


\section{Introduction}

Many of the most potent drugs and drug candidates are not water-soluble. Formulation of poorly soluble drugs such as paclitaxel (PTX) with a water solubility of approx. $1 \mu \mathrm{g} / \mathrm{mL}$ remains a major challenge in drug delivery [1-6]. Liposomes [4,7], micro- and nanoparticles [8] and polymer micelles $[1,2,5,9,10]$ have been studied intensively for this purpose, each approach having advantages and disadvantages. One major limitation of polymer micelles is the loading capacity and the total amount of drug that can be solubilized. The current clinical formulation of PTX, Taxol ${ }^{\circledR}$, contains less than $1 \%$ wt. of active drug but $99 \%$ of excipients known to cause considerable side effects for the patients [11,12]. The clinical alternative Abraxane ${ }^{\circledR}$ shows significant enhancement in this respect, however, still only approx. $10 \%$ of active drug are administered to the patients.

Poly(2-oxazoline)s (POx) have recently attracted considerable attention for biomedical applications [13-15]. Hydrophilic poly(2-methyl-2-oxazoline) (PMeOx) and poly(2-ethyl-2oxazoline) (PEtOx) are of particular interest as they exhibit stealth $[16,17]$ and protein repellent effects [18]. Moreover, PEtOx is approved by FDA as an indirect food additive. They also undergo rapid renal clearance [19] similar to poly(ethylene glycol), arguably the most commonly used polymer for injectable drug delivery systems and polymer therapeutics. However, in contrast to poly(alkylene glycol)s, the hydrophobicity of POx can be gradually fine-tuned over a broad range by alteration of the side chains, albeit depending on the molar mass and polymer architecture (Fig. 1A) [20,21]. Poly(2-butyl-2-oxazoline)s (PBuOx) are the first in the homologue series of POx that do not show considerable water solubility, although the amide motif at the polymer backbone provides a polar group in each repeating unit. The absence of a hydrogen bond donor in the polymer limits inter- and intramolecular interaction between polymer chains and leads to an excellent hydration of the polymer backbone [22, 23]. PTX and many other extremely water insoluble drugs contain many polar moieties. Therefore, we reasoned that a micellar environment that is water insoluble but feature polar groups for dipol interaction or H-bonding would be beneficial for the solubilization of such drugs. By an appropriate selection of 2-oxazoline monomers, block copolymers can be obtained which comprise an amphiphilic motif in the block copolymer architecture as well as in the repeating monomer unit of the hydrophobic block comprising BuOx. It will be shown that $\mathrm{BuOx}$ based micellar cores create a very unusual microenvironment and unprecedented high solubilization capacities for various water insoluble drugs.

\section{Materials and Methods}

All substances for the preparation of the polymers were purchased from Aldrich (Steinheim, Germany) or Acros (Geel, Belgium) and were used as received unless otherwise stated. 2Butyl-2-oxazoline was prepared as recently described [20]. Methyl trifluoromethylsulfonate (MeOTf), 2-methyl-2-oxazoline (MeOx), 2-ethyl-2-oxazoline (EtOx), acetonitrile (ACN) and other solvents for polymer preparation were dried by refluxing over $\mathrm{CaH}_{2}$ under dry nitrogen atmosphere and subsequent distillation prior to use. NMR spectra were recorded on a Bruker Avance III 400, Bruker ARX 300 or a Bruker AC 250 at room temperature. The spectra were calibrated using the solvent signals $\left(\mathrm{CDCl}_{3} 7.26 \mathrm{ppm}, \mathrm{D}_{2} \mathrm{O} 4.67 \mathrm{ppm}\right)$. Gel permeation chromatography (GPC) was performed on a Waters system (pump mod. 510, RI-detector mod. 410, precolumn PLgel and two PL Resipore colunms $(3 \mu \mathrm{m}, 300 \times 7,5 \mathrm{~mm}))$ with N,N-dimethyl acetamide (DMAc) $\left(57 \mathrm{mmol} / \mathrm{L} \mathrm{LiBr}, 80{ }^{\circ} \mathrm{C}, 1 \mathrm{~mL} / \mathrm{min}\right)$ as eluent and calibrated against PMMA standards. Dynamic light scattering was performed using a Zetasizer Nano-ZS (Malvern Instruments Inc., Southborough, MA) at room temperature. 


\section{Synthetic procedures}

The polymerizations and work-up procedures were carried out as described previously [24, 25].

Exemplary, the preparation of Methyl-P[MeOx $\left.27-b-\mathrm{BuOx}_{12}-\mathrm{b}-\mathrm{MeOx}_{27}\right]$-piperidine (P1) was performed as follows.

Under dry and inert conditions $32.2 \mathrm{mg}(0.2 \mathrm{mmol}, 1 \mathrm{eq})$ of methyl trifluoromethylsulfonate (methyl triflate, MeOTf) and $440 \mathrm{mg}(5.17 \mathrm{mmol}, 26 \mathrm{eq}$ ) of 2-methyl-2-oxazoline (MeOx) were dissolved in $3 \mathrm{~mL}$ dry acetonitrile at room temperature. The mixture was subjected to microwave irradiation ( $150 \mathrm{~W}$ maximum, $130{ }^{\circ} \mathrm{C}$ ) for $15 \mathrm{~min}$. After cooling to room temperature, the monomer for the second block, 2-butyl-2-oxazoline (256 mg, $2.01 \mathrm{mmol}, 10$ eq) were added and the mixture was irradiated the same way as for the first block. The procedure was repeated for the third block with $442 \mathrm{mg} \mathrm{MeOx}(5.19 \mathrm{mmol}, 26 \mathrm{eq})$. Finally, P1 was terminated by addition of $0.1 \mathrm{~mL}$ piperidine $(1.01 \mathrm{mmol}, 5 \mathrm{eq})$ at room temperature. After stirring over night, an access of $\mathrm{K}_{2} \mathrm{CO}_{3}$ was added and the mixture was allowed to stir for several hours. The solvent was removed after filtration and $3 \mathrm{~mL}$ of chloroform were added to the residue. After precipitation from cold diethyl ether (approx. 10 times the amount of polymer solution) the product was isolated by centrifugation. The precipitation was performed in triplicate and the polymer was obtained as colorless powder $\left(792 \mathrm{mg}, 67 \%, \mathrm{M}_{\mathrm{th}}=5.8 \mathrm{~kg} / \mathrm{mol}\right)$ after lyophilization from water. GPC (DMAc): $\mathrm{M}_{\mathrm{n}}=8.5 \mathrm{~kg} / \mathrm{mol}$ (PDI 1.21 ); ${ }^{1} \mathrm{H}-\mathrm{NMR}$ $\left(\mathrm{CDCl}_{3}, 298 \mathrm{~K}\right): \delta=3.45$ (br, $\left.255 \mathrm{H},\left(\mathrm{N}-\mathrm{CH}_{2} \mathrm{CH}_{2}\right)\right) ; 3.04 / 2.95$ (m, 3H, N-CH $\left.{ }_{3} \mathrm{Ini}\right) ; 2.43-1.86$ (m, 212H, CO-CH $\left.{ }_{3}, \mathrm{CO}-\mathrm{CH}_{2}, \mathrm{CH}_{2}{ }^{\mathrm{Pid}}\right) ; 1.56$ (br, $29 \mathrm{H},-\mathrm{CH}_{2}-\mathrm{CH}_{2}-\mathrm{CH}_{2}$ ); 1.32 (br, $28 \mathrm{H},-$ $\left.\mathrm{CH}_{2}-\mathrm{CH}_{3}\right) ; 0.91 \mathrm{ppm}\left(\mathrm{br}, 37 \mathrm{H},-\mathrm{CH}_{3}{ }^{\text {butyl }}\right), \mathrm{M}_{\mathrm{n}}=6.2 \mathrm{~kg} / \mathrm{mol}\left(\mathrm{MeOx}_{27}-\mathrm{b}-\mathrm{BuOx}_{12}-\mathrm{b}-\mathrm{MeOx}_{27}\right)$ Analytical data for polymers P1-P4 are summarized in Table 1.

Methyl-P[MeOx $\left.\mathbf{x}_{37}-\mathbf{b}-\mathrm{BuOx}_{23}-\mathrm{b}-\mathrm{MeO}_{\mathbf{3 7}}\right]$-piperidine (P2)—P2 was obtained accordingly using $24 \mathrm{mg} \mathrm{MeOTf}(0.146 \mathrm{mmol}, 1 \mathrm{eq}), 333 \mathrm{mg} \mathrm{MeOx}\left(3.91 \mathrm{mmol}, 27 \mathrm{eq}, 1^{\text {st }}\right.$ block), $286 \mathrm{mg} \mathrm{BuOx}$ (2.25 mmol, $15 \mathrm{eq}, 2^{\text {nd }}$ block) and $333 \mathrm{mg} \mathrm{MeOx} \mathrm{(3.91} \mathrm{mmol,} 27 \mathrm{eq}$, $3^{\text {rd }}$ block) and $80 \mu \mathrm{L}$ of piperidine as terminating reagent. The product was obtained as a colorless solid (795 mg, $\left.83 \%, \mathrm{M}_{\mathrm{th}}=6.6 \mathrm{~kg} / \mathrm{mol}\right)$.

GPC (DMAc): $\mathrm{M}_{\mathrm{n}}=10.4 \mathrm{~kg} / \mathrm{mol}$ (PDI 1.18); ${ }^{1} \mathrm{H}-\mathrm{NMR}\left(\mathrm{CDCl}_{3}, 298 \mathrm{~K}\right): \delta=3.44$ (br, 360H, $\left(\mathrm{N}-\mathrm{CH}_{2} \mathrm{CH}_{2}\right)$ ); 3.03/2.94 (m, 3H, N-CH$\left.{ }_{3}{ }^{\mathrm{Ini}}\right) ; 2.33-1.9$ (m, 279H, CO-CH 3 , CO-CH $\mathrm{CH}_{2}{ }^{\mathrm{Pid}}$ ); 1.55 (br, $47 \mathrm{H},-\mathrm{CH}_{2}-\mathrm{CH}_{2}-\mathrm{CH}_{2}-$ ); 1.32 (br, $45 \mathrm{H},-\mathrm{CH}_{2}-\mathrm{CH}_{3}$ ); $0.91 \mathrm{ppm}$ (br, $68 \mathrm{H}$, $\left.\mathrm{CH}_{3}{ }^{\text {butyl }}\right), \mathrm{M}_{\mathrm{n}}=9.3 \mathrm{~kg} / \mathrm{mol}\left(\mathrm{MeOx}_{37}-\mathrm{b}-\mathrm{BuOx}_{23}-\mathrm{b}-\mathrm{MeOx}_{37}\right)$.

Methyl-P[MeOx $\left.\mathbf{x}_{36}-\mathrm{b}-\mathrm{BuOx}_{\mathbf{3 0}}-\mathrm{b}-\mathrm{MeO}_{36}\right]$-piperidine (P3)-P3 was prepared accordingly using $24.7 \mathrm{mg}$ methyltriflate $(0.150 \mathrm{mmol}, 1 \mathrm{eq})$ and $334 \mathrm{mg}$ 2-methyl-2-oxazoline ( $3.9 \mathrm{mmol}, 26 \mathrm{eq}, 1^{\text {st }}$ block). An aliquot of $136 \mathrm{mg}(5 \% \mathrm{w} / \mathrm{w})$ of the reaction mixture where removed for analysis of the first block with NMR and GPC. The same procedure was performed after the second block (364.4 mg BuOx; $2.87 \mathrm{mmol}, 20 \mathrm{eq}, 10 \% \mathrm{w} / \mathrm{w}$ analyzed). Block three (306.9 mg MeOx; $3.6 \mathrm{mmol}, 28 \mathrm{eq}$ ) was added, the polymerization was terminated using 80 $\mu \mathrm{L}$ piperidine and the product was obtained as a colorless solid $\left(598 \mathrm{mg}, 65 \%, \mathrm{M}_{\mathrm{th}}=6.6 \mathrm{~kg} /\right.$ mol).

GPC (DMAc): $\mathrm{M}_{\mathrm{n}}=9.9 \mathrm{~kg} / \mathrm{mol}$ (PDI 1.23); ${ }^{1} \mathrm{H}-\mathrm{NMR}\left(\mathrm{CDCl}_{3}, 298 \mathrm{~K}\right): \delta=3.45$ (br, 405H, $\left(\mathrm{N}-\mathrm{CH}_{2} \mathrm{CH}_{2}\right)$ ); $3.03 / 2.95\left(\mathrm{~m}, 3 \mathrm{H}, \mathrm{N}-\mathrm{CH}_{3}{ }^{\mathrm{Ini}}\right) ; 2.43-1.86$ (m, 329H, CO-CH${ }_{3}, \mathrm{CO}-\mathrm{CH}_{2}$, $\mathrm{CH}_{2}{ }^{\mathrm{Pid}}$ ); 1.57 (br, $63 \mathrm{H},-\mathrm{CH}_{2}-\mathrm{CH}_{2}-\mathrm{CH}_{2}$ ); 1.32 (br, 60H, $-\mathrm{CH}_{2}-\mathrm{CH}_{3}$ ); $0.91 \mathrm{ppm}$ (br, 88H, $\left.\mathrm{CH}_{3}{ }^{\text {butyl }}\right), \mathrm{M}_{\mathrm{n}}=10.0 \mathrm{~kg} / \mathrm{mol}\left(\mathrm{MeOx}_{36}-\mathrm{b}-\mathrm{BuOx}_{30}-\mathrm{b}-\mathrm{MeOx}_{36}\right)$.

Methyl-P[EtOx $\mathbf{x}_{\mathbf{5 0}}$-b-BuOx $\left.\mathbf{1}_{\mathbf{1 9}}\right]$-piperazine (P4)—P4 was prepared accordingly from 10 $\mathrm{mg} \mathrm{MeOTf}$ ( $61 \mu \mathrm{mol}, 1 \mathrm{eq}), 321 \mathrm{mg}$ 2-ethyl-2-oxazoline (3.24 mmol, $53 \mathrm{eq}, \mathrm{1}^{\text {st }}$ block) and 157 
mg BuOx (1.23 mmol, $20 \mathrm{eq}, 2^{\text {nd }}$ block), using $150 \mathrm{mg}$ piperazine as a terminating reagent. For precipitation, a solvent mixture of cyclohexane and diethylether $(50 / 50, \mathrm{v} / \mathrm{v})$ was used. The product was obtained as a colorless solid (yield $0.36 \mathrm{~g}, 77 \%, \mathrm{M}_{\mathrm{th}}=7.8 \mathrm{~kg} / \mathrm{mol}$ ).

GPC (DMAc): $\mathrm{M}_{\mathrm{n}}=11.5 \mathrm{~kg} / \mathrm{mol}$ (PDI 1.09); ${ }^{1} \mathrm{H}-\mathrm{NMR}\left(\mathrm{CDCl}_{3}, 298 \mathrm{~K}\right): \delta=3.45$ (br, 276H, $\left(\mathrm{N}-\mathrm{CH}_{2} \mathrm{CH}_{2}\right)$ ); $3.04 / 2.95\left(\mathrm{~m}, 3 \mathrm{H}, \mathrm{N}-\mathrm{CH}_{3}{ }_{3}{ }^{\mathrm{Ini}}\right) ; 2.5-2.2\left(\mathrm{~m}, 144 \mathrm{H}, \mathrm{CO}-\mathrm{CH}_{2}-\mathrm{CH}_{3}, \mathrm{CO}-\mathrm{CH}_{2}\right.$, $\mathrm{CH}_{2}{ }^{\mathrm{Pid}}$ ); 1.58 (br, 37H, $-\mathrm{CH}_{2}-\mathrm{CH}_{2}-\mathrm{CH}_{2}$ ); 1.34 (br, $\left.41 \mathrm{H},-\mathrm{CH}_{2}-\mathrm{CH}_{3}\right) ; 1.11$ (br, $151 \mathrm{H}, \mathrm{CO}-$ $\left.\mathrm{CH}_{2}-\mathrm{CH}_{3}\right) ; 0.91 \mathrm{ppm}$ (br, $56 \mathrm{H},-\mathrm{CH}_{3}{ }^{\text {butyl }}$ ), $\mathrm{M}_{\mathrm{n}}=7.5 \mathrm{~kg} / \mathrm{mol}\left(\mathrm{EtOx}_{50} 0^{-b}-\mathrm{BuOx}_{19}\right)$.

\section{Pyrene Fluorescence measurements}

The $\mathrm{cmc}$ was determined using standard procedure [26,27]. In short, a pyrene solution in acetone $(2.5 \mathrm{mM})$ was added to vials and the solvent was allowed to evaporate. Polymer solutions at appropriate concentrations in assay buffer were added to the vials so that a final concentration of $5 \times 10^{-7} \mathrm{M}$ of pyrene was obtained. The solutions were incubated at $25^{\circ} \mathrm{C}$ $(>2 \mathrm{~h})$ and the pyrene fluorescence spectra were recorded using a Fluorolog3 (HoribaJobinYvon) $\lambda_{\mathrm{ex}}=333 \mathrm{~nm}, \lambda_{\mathrm{em}}=360-400 \mathrm{~nm}$, slidwidth $(\mathrm{ex})=\operatorname{slidwidth}(\mathrm{em})=1 \mathrm{~nm}$, step width $0.5 \mathrm{~nm}$. Typically, five spectra of each data point were averaged (integration time $0.1 \mathrm{~s}$, if necessary 10 spectra with $0.2 \mathrm{~s}$ integration), the $\mathrm{cmc}$ is assumed where a steep increase in fluorescence intensity is observed. Furthermore, the fluorescence intensity of the $I_{1}$ band was compared to the intensity of $\mathrm{I}_{3}$ band which gives an estimate of the polarity of the environment of the pyrene probe. No excimer band formation was observed.

\section{Drug solubilization studies}

Paclitaxel (PTX) solubilization-Drug-polymer solutions were prepared using the thin film method. Appropriate amounts of polymer and PTX (Sigma-Aldrich, St. Louis, MO, order number T7191) (stock solution 5-8 $\mathrm{mg} / \mathrm{mL}$ in ACN or ethanol) were solubilized in minimum amounts of ACN or ethanol, alternatively. After complete removal of the solvent, the films dried in vacuo ( $0.2 \mathrm{mbar}$ ) for at least $3 \mathrm{~h}$ to remove residual solvent. Subsequently $200 \mu \mathrm{L}$ of assay buffer (aqueous solution, containing $122 \mathrm{mM} \mathrm{NaCl}, 25 \mathrm{mM} \mathrm{Na}_{2} \mathrm{CO}_{3}, 10 \mathrm{mM}$ HEPES, $10 \mathrm{mM}$ Glucose, $3 \mathrm{mM} \mathrm{KCl}, \mathrm{CaCl}_{2} 1.4 \mathrm{mM}$ and $\mathrm{K}_{2} \mathrm{HPO}_{4} 0.4 \mathrm{mM}, \mathrm{pH}=7.4$ ) were added to obtain final polymer concentration as mentioned in the main text. At higher PTX concentration solubilization was facilitated by incubation of the solutions at $50-60{ }^{\circ} \mathrm{C}$ for typically $5-10$ min. The clear solutions were filtered through HPLC syringe filters $(0.45 \mu \mathrm{m}$ pore size $)$ and subjected to HPLC analysis

Solubilization of Cyclosporin A, and Etoposide-Solubilization of Cyclosporin A (Alexis Corporation San Diego, CA, order number 380-002-G001) and Etoposide (SigmaAldrich, St. Louis, MO, order number E1398) was performed accordingly using the film method. In the case of Etoposide solubilization, a clear solution was obtained at concentrations of $1 \mathrm{mg} / \mathrm{mL}$ drug and $10 \mathrm{mg} / \mathrm{mL} \mathrm{P2}$ upon addition of water. However, after approx. $1 \mathrm{~min}$ the drug precipitated out of the formulations.

Solubilization of Amphotericin B-We were unable to find a common solvent for polymers P1-P4 and amphotericin B with a reasonable high vapor pressure. Thus, solubilization of amphotericin B with $\mathbf{P 2}$ was performed via solvent exchange by dialysis. P2 (10.2 mg) and amphotericin B trihydrate (2.1 mg, Riedel-de Haën, Seelze, Germany, order number 46006) were dissolved in $250 \mu \mathrm{L}$ dimethylsulfoxide (DMSO) to yield a clear, yellow solution. A total of $750 \mu \mathrm{L}$ of deionized water was added, after $100 \mu \mathrm{L}$ the mixture became turbid. The resulting mixture was transferred into a dialysis bag (MWCO $3500 \mathrm{~g} / \mathrm{mol}$ ). The solution was dialyzed against $2 \mathrm{~L}$ deionized water (water exchanged at $2 \mathrm{~h}, 4 \mathrm{~h}$ and $22 \mathrm{~h}$ ). After a total of $50 \mathrm{~h}$, the suspension $(4 \mathrm{~mL})$ was recovered from the bag. An aliquot of $500 \mu \mathrm{L}$ was filtered $(0.45 \mu \mathrm{m})$ to remove particles and the clear, yellow solution was freeze dried to yield 
$1 \mathrm{mg}$ of yellow foam-like solid. The residue was dissolved in $200 \mu \mathrm{L}$ DMSO and the amphotericin B was quantified spectrophotometrically using the absorbance at $410 \mathrm{~nm}$. The dialyzed solution contained $366 \mu \mathrm{g}$ Amphotericin B (18\% (w/w) with respect to P2). Another aliquot of $1 \mathrm{~mL}$ was freeze-dried (2.2 mg yellow foam) and dissolved subsequently in $100 \mu \mathrm{L}$ deionized water. The polymer-drug foam dissolved rapidly and completely to give an intense yellow solution of low viscosity. Thus, without the need for cryoprotectants, $3.7 \mathrm{mg} / \mathrm{mL}$ of Amphotericin B could be solubilized using only $18.3 \mathrm{mg} / \mathrm{mL}$ P2. Using the same protocol, water solubility of Amphotericin B was determined to be approx. $0.4 \mu \mathrm{g} / \mathrm{mL}$.

HPLC analysis of drug solubilization-HPLC analysis was carried out under isocratic conditions using a Shimadzu system comprising a SCL-10A system controller, SIL-10A autoinjector, SPD-10AV UV detector and two LC-10 AT pumps. As stationary phase a Nucleosil C18-5 $\mu$ column was used $(250 \mathrm{~mm} \times 4 \mathrm{~mm})$, for PTX analysis a mobile phase of acetonitrile/water mixture (55/45, v/v) was applied. HPLC analysis of Cyclosporin A solutions obtained were performed using as a mobile phase an acetonitrile/water mixture $(90 / 10, \mathrm{v} / \mathrm{v})$ at $70{ }^{\circ} \mathrm{C}$. Detection was performed at $220 \mathrm{~nm}$.

\section{Cell culture and cytotoxicity}

MCF7/ADR cell line was obtained (derived from human breast carcinoma cell line, MCF7 (ATCC HT-B22)) by selection with Doxorubicin and was kindly presented by Y.L. Lee (William Beaumont Hospital, Royal Oak, MI). Cells were maintained in Dulbecco's Modified Eagle's Medium (DMEM), containing 10\% heat inactivated fetal bovine serum (FBS) and 1\% penicillin/streptomycin. All tissue material media was obtained from Gibco Life Technologies, Inc. (Grand Island, NY). Cytotoxicity was assessed using standard MTT assay. Each concentration was tested in four wells, data is presented in mean \pm SEM.

\section{Complement activation}

To evaluate the complement activation mediated in vitro by POx, we determined the levels of C3a-desArg in human serum. The concentration of C3a-desArg was assessed for each formulation using an enzyme-linked immunosorbent assay kit (Human C3a ELISA Kit, BD Biosciences, San Jose, CA) according to the manufacturers protocol. For each measurement, poly-(2-oxazoline)s or CrEl based formulations were first suitably diluted in sterile PBS solution. P1-P4 were used at a concentration of $7.5 \mathrm{mg} / \mathrm{mL}$; the formulation combining P2 and PTX (P2-PTX) contained $7.5 \mathrm{mg} / \mathrm{ml}$ of P2 and $3 \mathrm{mg} / \mathrm{mL}$ of PTX. The commercial solution of PTX (Taxol®) was diluted 2 times in order to reach a concentration of PTX of $3 \mathrm{mg} / \mathrm{mL}$. The concentration of the excipient $\mathrm{CrEl}$ in this sample was thus $263.5 \mathrm{mg} / \mathrm{mL}$. The same concentration was used for the tests performed with $\mathrm{CrEl}$ alone (solubilized in ethanol).

To perform the experiment, $10 \mu \mathrm{L}$ of each sample were mixed with $40 \mu \mathrm{L}$ of non diluted human serum (Human Serum Complement, Quidel Corp., San Diego, CA) and incubated in sterile Eppendorf tubes for 30 minutes at $37^{\circ} \mathrm{C}$. Diluting the samples in the provided diluent 20,000 times stopped the reaction. Serum was mixed with sterile PBS (at the same ratio and volume previously used) to serve as a negative control and Zymosan (final concentration: $5 \mathrm{mg} / \mathrm{mL}$, Sigma-Aldrich, Saint-Louis, MO) provided a positve control over complement activation. For each sample, 6 independent measurements were carried out. Concentrations of C3a-desArg are presented as mean \pm standard deviation. Statistical significance between the various groups was assessed using Student's unpaired t-test. Differences between groups were considered significant at $\mathrm{p}<0.05$.

\section{Animal studies}

All experiments were performed using female C57/Bl/6 mice 11-12 weeks of age (Taconic Laboratories, Germantown, NY). The animals were kept five per cage with an air filter cover 
under light (12-h light/dark cycle) and temperature-controlled (22F1 8C) environment. All manipulations with the animals were performed under a sterilized laminar hood. Food and water were given ad libitum. The animals were treated in accordance to the Principles of Animal Care outlined by National Institutes of Health, and protocols were approved by the Institutional Animal Care and Use Committee of the University of Nebraska Medical Center. Lewis lung carcinoma cells (LLC 3T) were grown in T75 flasks and collected with HBSS. Cell suspensions $\left(1 \times 10^{6}\right.$ per animal) were injected subcutaneously in a volume of $50 \mu \mathrm{L}$ on the right flank. After tumors appeared, tumor sizes where recorded (day 1) and treatment solutions were injected at a dose of $10 \mathrm{mg} / \mathrm{kg}$ PTX in a volume of $100 \mu \mathrm{L}$ on day 1,4 and 7.

\section{Results and Discussion}

\section{Polymer synthesis and characterization}

Three well-defined ABA-type triblock copolymers (P1-P3) and one AB-diblock copolymer (P4) with defined low molar masses (around $10 \mathrm{~kg} / \mathrm{mol}$ ) and low polydispersities $\left(\mathrm{PDI}=\mathrm{M}_{\mathrm{W}} /\right.$ $\mathrm{M}_{\mathrm{n}}=1.09-1.23$ ) were synthesized by living cationic ring-opening polymerization. The hydrophilic blocks (A) consist of 50 to 74 units of PMeOx (P1-P3) or PEtOx (P4), and the hydrophobic blocks (B) of 12 to 30 units of PBuOx (Fig. 1B). The analytical data are summarized in Table 1.

\section{Drug solubilization}

Interestingly, polymer micelles of these polymers spontaneously formed in water exhibited a remarkable capability for solubilization of PTX (water solubility $\approx 1 \mu \mathrm{g} / \mathrm{mL}$ ). To prepare drug loaded polymeric micelles we used the thin-film dissolution method. Initially, we attempted to solubilize 4, 7 and $10 \mathrm{mg} / \mathrm{mL}$ PTX with $10 \mathrm{mg} / \mathrm{mL}$ of P2. Up to concentrations of $7 \mathrm{mg} / \mathrm{mL}$ PTX, completely clear solutions were obtained after mild heating (approx. $60{ }^{\circ} \mathrm{C}$ ) for a short time. Under these conditions the solubilization of PTX was complete as confirmed by high performance liquid chromatography (HPLC) (Fig. 2A).

Only at $10 \mathrm{mg} / \mathrm{mL}$ PTX some clear crystals remained undissolved even after 30 min heating at $60{ }^{\circ} \mathrm{C}$. However, still an extraordinary amount of $8.2 \mathrm{mg} / \mathrm{mL}$ of PTX was found in the aqueous phase after removal of undissolved solid, in other words, the resulting formulation consists of $45 \%$ wt. PTX. Similar results were obtained with the other polymers including P1, having a relatively short BuOx block (Fig. 2B).

Even at polymer concentration as low as $2 \mathrm{mg} / \mathrm{mL}$, excellent loading efficiencies, PTX concentrations of $0.8 \mathrm{mg} / \mathrm{mL}$ and total drug loading of about $30 \% \mathrm{wt}$. were obtained (Fig. 2C, D). Thus, using doubly-amphiphilic POx block copolymer nanoformulations reduces the amount of excipient needed to solubilize PTX by almost one order ( 7.5 fold) as compared to Abraxane ${ }^{\mathrm{TM}}$ or two orders of magnitude as compared to Cremophor EL/ethanol (CrEL). Interestingly, we found that a regular amphiphilic block copolymer with a hydrophobic block having longer pendant n-alkyl side chains (2-nonyl-2-oxazoline, NOx) [28] solubilized considerably less PTX (7 \% wt./0.74 mg/mL for $\mathrm{P}\left(\mathrm{MeOx}_{32}-\mathrm{b}-\mathrm{NO} \mathrm{x}_{9}\right)$ ). Our results relate to earlier studies on surfactant systems [29] and solubility studies [30] for PTX and docetaxel. It was found that the solubility of the drugs increases as the length of the hydrocarbons of the solvent decreases. It was further suggested that hydrogen bonding enhance the solubilization also in an otherwise apolar environment. We also investigated the potential of the POx amphiphiles to solubilize other highly hydrophobic, but structurally very different drugs containing several polar motifs, i.e. Cyclosporin A, Amphotericin B, and Etoposide. With Etoposide, no stable formulation could be obtained. Although initially we observed clear solutions with Etoposide concentrations of $1 \mathrm{mg} / \mathrm{mL}$ and polymer concentrations of $10 \mathrm{mg} /$ $\mathrm{mL}$, the dissolved drug precipitated rapidly within minutes. However, both other drugs could 
be successfully solubilized in water giving stable formulations of similar high drug content (3.7 mg/mL Amphotericin B (17 \% wt.); $1 \mathrm{mg} / \mathrm{mL}$ Cyclosporin A (17 \% wt.)). Such formulations could be freeze-dried and redispersed readily in water without addition of cryoprotectants.

To the best of our knowledge, such high loading and loading efficiency in combination with the high solubility of PTX is unprecedented for simple micellar or liposomal drug delivery systems. For example, very recently Lam and co-workers reported on a PEG-based telodendrimeric system with high loading and solubilization capacity [31]. The authors were able to obtain similar high PTX concentrations $(7.3 \mathrm{mg} / \mathrm{mL})$, albeit using twice the amount of polymer excipient $(20 \mathrm{mg} / \mathrm{mL})$ compared to our studies. Moreover, the synthesis of such telodendrimer systems requires multistep ( 7 steps) liquid phase polymer analog coupling reactions. Including monomer synthesis, the here-described polymers are prepared in two steps in high yields from readily available and inexpensive starting materials and can be obtained in multi-gram scale.

\section{Physicochemical properties of the POx doubly amphiphilic micelles}

We hypothesized that the high loading is due to the presence of a unique micellar microenvironment providing non-polar as well as polar and hydrogen bonding interactions in the core between the drug and the doubly-amphiphilic BuOx segment. The hydrophobic and solvatochromic [32,33] fluorescence probe pyrene is commonly used to investigate the formation of micelles and to probe the microenvironment (i.e. polarity) of the micelle interior and/or interface $[26,27]$. Using this approach, we found low critical micelle concentrations (cmc) ranging from $100 \mathrm{mg} / \mathrm{L}(15 \mu \mathrm{M}, \mathbf{P 1}), 20 \mathrm{mg} / \mathrm{L}(2.7 \mu \mathrm{M}, \mathbf{P 2}), 7 \mathrm{mg} / \mathrm{L}(1 \mu \mathrm{M}, \mathbf{P 3})$ to 6 $\mathrm{mg} / \mathrm{L}(0.7 \mu \mathrm{M}, \mathbf{P 4})$, respectively (Fig. 3A-D). However, the fluorescence characteristics of pyrene we observed, as the polymer concentrations increased were highly unusual. The ratio of the $I_{1}$ and $I_{3}$ band in the fluorescence emission spectrum of pyrene is used as a measure of the polarity $[26,27,32,33]$ of the environment of the pyrene probe. In aqueous or similarly polar environment this ratio is found between 1.6 and 1.9 (Fig. 4A) [26,27,32-35]. For regular polymer micelles, the less polar environment of the core results in a characteristic decrease of the $\mathrm{I}_{1} / \mathrm{I}_{3}$ ratio along with increasing fluorescence intensity. Quite surprisingly, for micelles formed by the doubly-amphiphilic polymers P1-P4, we observed the opposite as the $\mathrm{I}_{1} / \mathrm{I}_{3}$ ratio increased up to 2.35 (Fig. 3). To the best of our knowledge, such high values have not been reported for polymeric micelles or any other media. The observed $\mathrm{I}_{1} / \mathrm{I}_{3}$ ratio, indicate that the fluorescent probe environment is even more polar than observed for e.g. dimethylsulfoxide, or an ionic liquid such as 1-butyl-2,3-dimethylimidazolium chloride, rather than unpolar as in the case of regular polymeric micelles of e.g. Pluronic $\mathrm{P} 85\left(\mathrm{I}_{1} / \mathrm{I}_{3} \approx 1.3\right)$ or $\mathrm{PMeOx}_{32} \mathrm{NOx}_{9}\left(\mathrm{I}_{1} / \mathrm{I}_{3}\right.$ $\approx 1.2$ ) (Fig. S1) [28]. Maeda and co-workers reported on pyrene fluorescence with similar systems as described here [36]. The authors also observed a large increase in fluorescence intensity measured at $374 \mathrm{~nm}$ in presence of the polymers. Unfortunately, however, no $\mathrm{I}_{1} / \mathrm{I}_{3}$ ratios are given in this account. Moreover, the authors describe the incorporation of enzymes such lipases in polymers very similar to $\mathbf{P 4}$, and report that polymer incorporated enzymes show a higher activity compared to native enzymes, both in aqueous and organic media [37]. The same group also investigated the interaction of serum albumin with POx based amphiphiles and it was shown that BuOx containing polymers lead to much smaller interaction with serum albumin as compared to polymers with more hydrophobic side chains (phenyl or octyl) [38].

We attribute the high loading to the combination of short, flexible hydrophobic side chains with the flexible, polar and well-hydrated polymer backbone present in the micellar core (Fig. 4B). The flexible butyl side chains stand in contrast to rather rigid 2-nonyl-2-oxazoline side chains that result in stretched, comb-like polymer chains and frozen micellar cores [24,28] that were found to solubilize much less PTX and gave typical $\mathrm{I}_{1} / \mathrm{I}_{3}$ values $(\approx 1.2)$. On the other 
hand, Pluronic ${ }^{\circledR}$ block copolymers, having simply a methyl side chain also fail to solubilized larger amounts of PTX $[39,40]$.

The relatively high mobility accessibility of the BuOx side chains was observed by ${ }^{1} \mathrm{H}-\mathrm{NMR}$ spectroscopy studies (Fig. S2). Comparison of the spectra of the polymers obtained under conditions when aggregates are present $\left(\mathrm{D}_{2} \mathrm{O}\right.$ as solvent $)$ or not $\left(\mathrm{CDCl}_{3}\right.$ as solvent), the signals of the butyl side chains are somewhat attenuated yet clearly observable when aggregates are formed. In contrast, Lee et al. report that in the case of P[EtOx-b-( $\varepsilon$-caprolactone)]-PTX formulations, the hydrophobic $\varepsilon$-caprolactone block is not detected by ${ }^{1} \mathrm{H}-\mathrm{NMR}$ spectroscopy, suggesting a much less flexible and accessible micellar core. In support of our hypothesis, these formulations could incorporate and solubilize only small amounts of PTX [41].

The present drug loaded micelles were found to be very small $\left(\mathrm{r}_{\mathrm{h}}=12-22 \mathrm{~nm}\right)$ and uniform (monomodal, narrow size distribution, $\mathrm{PD} \approx 0.04-0.12$ ) as determined by dynamic light scattering (Fig. S3). Such small and narrowly dispersed micellar systems are excellently suited for biomedical applications, i.e. for systemic administration.

\section{In vitro cytotoxicity and complement activation}

The polymers alone were found to be non-cytotoxic at concentrations of up to $20 \mathrm{mg} / \mathrm{mL}$ and for $24 \mathrm{~h}$ incubation using different cell lines (Fig. S4). In contrast to the plain polymers, the PTX-loaded micelles displayed a pronounced, concentration-dependent toxicity with respect to tumor cell lines (Fig. 5A). For example, after $24 \mathrm{~h}$ incubation with PTX-loaded P2-P4, we observed $\mathrm{IC}_{50}$ values in the range of $10 \mu \mathrm{M}$ using a multi-drug resistant cell line (MCF7/ADR). Commercially available CrEL-PTX formulation was used as a control and resulted in comparable growth inhibition (data not shown). Importantly, the PTX-loaded micelles could be lyophilized without the need for cryoprotectants and simply be redispersed in water or saline to give a completely clear solution without compromising the drug loading, the particle size or the in vitro drug activity (Fig. 5B). Complement activation is a major limitation of synthetic material for biomedical applications. Thus, P1-P4 as well as CrEL were submitted to an in vitro evaluation of complement activation in human serum. The concentrations of CrEL and P1-P4 used in this experiment allowed for the solubilization of the same concentration of PTX $(3 \mathrm{mg} / \mathrm{mL})$ as outlined in the methods section.

All POx samples tested, provided a small but significant increase in the C3a-desArg concentration compared to PBS (1.8 - 2.3 fold), albeit much lower than the positive control, Zymosan (5.1 fold) (Fig. 6). However, significantly lower levels of C3a-desArg were found after incubation with P1-P4 as compared to levels observed after incubation with CrEL (3.3 fold vs. PBS). It should be noted, that $\mathbf{P 4}$ (bearing PEtOx in the hydrophilic block) showed a slight increase of the complement activation compared to the three other POx (P1-P3, all comprising PMeOx in the hydrophilic blocks). This preliminary study on the complement activation does not give enough information to speculate on the mechanism of complement interaction with POx. However, it can be expected that increased complement activation leads to higher RES uptake and reduced stealth effect. Thus, our results are in line with earlier results that the slightly amphiphilic PEtOx gives faster clearance when used as liposomal coating $[16,17]$ and increased (albeit very low) non-specific organ uptake as compared to PMeOx [19].

Solubilization of PTX with P2 (i.e. P2-PTX) and CrEL (i.e. Taxol®) increased levels of C3adesArg in both cases significantly. However, P2-PTX (2.4 fold vs. PBS) displayed still lower concentrations of C3a-desArg than CrEL alone or Taxol® (4.1 fold vs. PBS). Thus, these complement activation studies were promising given the potential deleterious effects of complement activation after intravascular administration, i.e. dispnea, fever, hypertension, hypotension, hypoxemia, rash, respiratory distress, etc. [42]. In summary, the presented 
formulations combine facile, one-step preparation, unprecedented loading capacity for PTX and very low toxicity and complement activation. This prompted us to investigate this new carrier in vivo in tumor bearing mice.

\section{Tumor inhibition in vivo in tumor bearing mice}

The in vivo anti-tumor effect of PTX-loaded micelles was examined in C57/B1/6 mice with subcutaneous Lewis Lung carcinoma tumors (Fig. 7). Both CrEL and POx-PTX (P2-PTX) formulations significantly $(\mathrm{p}<0.05)$ decreased tumor burden after only one injection (day 4 , tumor inhibition $=72 \%$ and $63 \%$, respectively). The tumors in the P2-PTX treated animals remained significantly smaller $(\mathrm{p}<0.05)$ than in the animals treated with the commercial product between days 11 and 25. We found the tumor inhibition by P2-PTX in this period to be approximately $70 \%$ as compared to $50-60 \%$ in the CrEl group. After 28 days, however, a sharp increase in the tumor burden of the animals in the P2-PTX regimen was observed and the same tumor inhibition in both treated groups was found.

Reducing the amount of excipient needed to deliver potent drugs decreases the risk of side effects and a higher solubility allows for significantly shorter infusion times for patient benefit. We are currently investigating the solubilization of a greater variety of hydrophobic drugs and the influence of the polymer architecture to gain further insight into the solubilization of hydrophobic drugs using tailored doubly amphiphilic polymers.

Another approach to improve the therapeutic outcome of polymer micelles and other drug delivery systems is the implementation of active targeting. Either low-molar mass ligands (e.g. folate, RGD-peptides) or antibodies are attached to the polymers, typically to the hydrophilic terminus. While we did not employ such active targeting for the present study, the cationic ring opening of 2-oxazolines is ideal for such an endeavor. Chemically reactive moieties can be incorporated in any part of the polymers, using either functional initiators [43], monomers $[25,44,45]$ or terminating reagents [46]. In particular, we reported on the introduction and application of chemical moieties suitable for chemoselective ligations such as click-chemistry [25,47], oxim-ligation [44] and thiol-maleimide condensation [48].

\section{Conclusion}

In this work we present the synthesis and characterization of well-defined doubly amphiphilic block copoly(2-oxazoline)s with unique properties. The microenvironment formed by these polymers in aqueous solution appears to by more polar then water as probed with the pyrene assay. At the same time, we observed an unprecedented high solubilization capacity for highly water insoluble drugs such as Paclitaxel, Amphotericin B and Cyclosporin A. Formulations containing up to $45 \mathrm{wt} . \%$ of active drug could be obtained with very good loading efficiencies. In vitro and in vivo experiments suggest that the incorporated PTX remains fully active. We believe that the facile synthesis, excellent water solubility and high loading capacity in combination with formulation stability, low toxicity, limited complement activation and excellent preliminary in vivo drug efficacy makes such poly(2-oxazoline)s excellent candidates for further investigations, especially, but not only in the context of drug delivery.

\section{Supplementary Material}

Refer to Web version on PubMed Central for supplementary material.

\section{Acknowledgments}

Supported by the National Institutes of Health (2RO1 CA89225), the Department of Defence (USAMRMC 06108004) and the Deutsche Forschungsgemeinschaft (Forschergruppe FOR 411 "Radionuklidtherapie"). R.L. is grateful to the 
Deutschen Akademischen Austauschdienst (DAAD) for a postdoctoral scholarship. We also thank the Confocal Laser Scanning Microscope and Cell Analysis Core Facility at UNMC, UNMC Program of Excellence (POE) and the Nebraska Research Initiative (NRI). The authors would also like to thank K. Lüdtke for the preparation of P [(NOx) $\left.10(\mathrm{MOx})_{32}\right]$, S. Huber for the synthesis of BuOx and D. Alakhova and G. Sahay for technical assistance with cell culture experiments.

\section{References}

1. Savic R, Luo L, Eisenberg A, Maysinger D. Micellar nanocontainers distribute to defined cytoplasmic organelles. Science 2003;300(5619):615-8. [PubMed: 12714738]

2. Kabanov AV, Vinogradov SV. Nanogels as pharmaceutical carriers: Finite networks of infinite capabilities. Angew Chem Int Ed 2009;48(30):5418-29.

3. Dabholkar RD, Sawant RM, Mongayt DA, Devarajan PV, Torchilin VP. Polyethylene glycolphosphatidylethanolamine conjugate (PEG-PE)-based mixed micelles: Some properties, loading with paclitaxel, and modulation of p-glycoprotein-mediated efflux. Int J Pharm 2006;315(1-2):148-57. [PubMed: 16616818]

4. Yang T, Cui FD, Choi MK, Cho JW, Chung SJ, Shim CK, et al. Enhanced solubility and stability of pegylated liposomal paclitaxel: In vitro and in vivo evaluation. Int J Pharm 2007;338(1-2):317-26. [PubMed: 17368984]

5. Torchilin VP. Targeted polymeric micelles for delivery of poorly soluble drugs. Cell Mol Life Sci 2004;61(19-20):2549-59. [PubMed: 15526161]

6. Haag R. Supramolecular drug-delivery systems based on polymeric core-shell architectures. Angew Chem Int Ed 2004;43(3):278-82.

7. Wu J, Liu Q, Lee RJ. A folate receptor-targeted liposomal formulation for paclitaxel. Int J Pharm 2006;316(1-2):148-53. [PubMed: 16564654]

8. Desai NP, Trieu V, Hwang LY, Wu R, Soon-Shiong P, Gradishar WJ. Improved effectiveness of nanoparticle albumin-bound (nab) paclitaxel versus polysorbate-based docetaxel in multiple xenografts as a function of HER2 and SPARC status. Anticancer Drugs 2008;19(9):899-909. [PubMed: 18766004]

9. Kataoka K, Harada A, Nagasaki Y. Block copolymer micelles for drug delivery: Design, characterization and biological significance. Adv Drug Deliv Rev 2001;47(1):113-31. [PubMed: 11251249]

10. Matsumura Y, Kataoka K. Preclinical and clinical studies of anticancer agent-incorporating polymer micelles. Cancer Sci 2009;100(4):572-9. [PubMed: 19462526]

11. Gelderblom H, Verweij J, Nooter K, Sparreboom A, Cremophor EL. The drawbacks and advantages of vehicle selection for drug formulation. Eur J Cancer 2001;37(13):1590-8. [PubMed: 11527683]

12. Hennenfent KL, Govindan R. Novel formulations of taxanes: A review. Old wine in a new bottle? Ann Oncol 2006;17(5):735-49. [PubMed: 16364960]

13. Hoogenboom R. Poly(2-oxazoline)s: A polymer class with numerous potential applications. Angew Chem Int Ed 2009;48(43):7978-94.

14. Wang CH, Wang WT, Hsiue GH. Development of polyion complex micelles for encapsulating and delivering amphotericin B. Biomaterials 2009;30(19):3352-8. [PubMed: 19299011]

15. Schlaad H, Diehl C, Gress A, Meyer M, Demirel AL, Nur Y, et al. Poly (2-oxazoline) s as smart bioinspired polymers. Macromol Rapid Comm. 201010.1002/marc.200900683

16. Zalipsky S, Hansen CB, Oaks JM, Allen TM. Evaluation of blood clearance rates and biodistribution of poly (2-oxazoline)-grafted liposomes. J Pharm Sci 1996;85(2):133-7. [PubMed: 8683436]

17. Woodle MC, Engbers CM, Zalipsky S. New amphipatic polymer-lipid conjugates forming longcirculating reticuloendothelial system-evading liposomes. Bioconjug Chem 1994;5(6):493-6. [PubMed: 7873652]

18. Konradi R, Pidhatika B, Mühlebach A, Textor M. Poly-2-Methyl-2-Oxazoline: A peptide-like polymer for protein-repellent surfaces. Langmuir 2008;24(3):613-6. [PubMed: 18179272]

19. Gaertner FC, Luxenhofer R, Blechert B, Jordan R, Essler M. Synthesis, biodistribution and excretion of radiolabeled poly(2-alkyl-2-oxazoline)s. J Control Release 2007;119(3):291-300. [PubMed: 17451833] 
20. Huber S, Jordan R. Modulation of the lower critical solution temperature of 2-alkyl-2-oxazoline copolymers. Colloid Polym Sci 2008;286(4):395-402.

21. Zhang N, Huber S, Schulz A, Luxenhofer R, Jordan R. Cylindrical molecular brushes of poly (2oxazoline) s from 2-isopropenyl-2-oxazoline. Macromolecules 2009;42(6):2215-21.

22. Hoogenboom R, Thijs HML, Wouters D, Hoeppener S, Schubert US. Tuning solution polymer properties by binary water-ethanol solvent mixtures. Soft Matter 2008;4(1):103-7.

23. Noskov SY, Lamoureux G, Roux B. Molecular dynamics study of hydration in ethanol-water mixtures using a polarizable force field. J Phys Chem B 2005;109(14):6705-13. [PubMed: 16851754]

24. Bonné TB, Lüdtke K, Jordan R, Papadakis CM. Effect of polymer architecture of amphiphilic poly (2-oxazoline) copolymers on the aggregation and aggregate structure. Macromol Chem Phys 2007;208(13):1402-8.

25. Luxenhofer R, Jordan R. Click chemistry with poly (2-oxazoline)s. Macromolecules 2006;39(10): 3509-16.

26. Colombani O, Ruppel M, Schubert F, Zettl H, Pergushov DV, Müller AHE. Synthesis of poly (nbutyl acrylate)-block-poly (acrylic acid) diblock copolymers by ATRP and their micellization in water. Macromolecules 2007;40(12):4338-50.

27. Kabanov AV, Nazarova IR, Astafieva IV, Batrakova EV, Alakhov VY, Yaroslavov AA, et al. Micelle formation and solubilization of fluorescent probes in poly (oxyethylene-b-oxypropylene-boxyethylene) solutions. Macromolecules 1995;28(7):2303-14.

28. Ivanova R, Komenda T, Bonné TB, Lüdtke K, Mortensen K, Pranzas PK, et al. Micellar structures of hydrophilic/lipophilic and hydrophilic/fluorophilic poly (2-oxazoline) diblock copolymers in water. Macromol Chem Phys 2008;209(21):2248-58.

29. Kan P, Chen ZB, Lee CJ, Chu IM. Development of nonionic surfactant/phospholipid o/w emulsion as a paclitaxel delivery system. J Control Release 1999;58(3):271-8. [PubMed: 10099152]

30. Huynh L, Grant J, Leroux JC, Delmas P, Allen C. Predicting the solubility of the anti-cancer agent docetaxel in small molecule excipients using computational methods. Pharm Res 2008;25(1):14757. [PubMed: 17705028]

31. Xiao K, Luo J, Fowler WL, Li Y, Lee JS, Xing L, et al. A self-assembling nanoparticle for paclitaxel delivery in ovarian cancer. Biomaterials 2009;30(30):6006-16. [PubMed: 19660809]

32. Dong DC, Winnik MA. The py scale of solvent polarities. Solvent effects on the vibronic fine structure of pyrene fluorescence and empirical correlations with $\mathrm{E}_{\mathrm{T}}$ and $\mathrm{Y}$ values. Photochem Photobiol 1982;35(1):17-21.

33. Kalyanasundaram K, Thomas JK. Environmental effects on vibronic band intensities in pyrene monomer fluorescence and their application in studies of micellar systems. J Am Chem Soc 1977;99 (7):2039-44.

34. The ratio varies significantly between different accounts in the literature. It has been shown that it is influenced both by environmental and instrumental conditions.

35. Street KW, Acree WE. Experimental artifacts and determination of accurate py values. Analyst 1986;111(10):1197-201.

36. Naka K, Kubo Y, Ohki A, Maeda S. Aggregate of amphiphilic block copolymer derived from poly [(n-acylimino)ethylene]s and guest-binding properties for 8-anilino-1-naphthalenesulfonic acid, pyrene, and enzymes. Polymer J 1994;26(3):243-9.

37. Naka K, Yamashita R, Nakamura T, Ohki A, Maeda S, Aoi K, et al. Aggregates of peptide-containing block copolymers and their interactions with a lipase in aqueous solution. Macromol Chem Phys 1997;198(1):89-100.

38. Naka K, Nakamura T, Ohki A, Maeda S. Aggregation behavior and interaction with human serum albumin of 2-oxazoline block copolymers in aqueous solutions. Macromol Chem Phys 1997;198(1): $101-16$

39. Wang Y, Yu L, Han L, Sha X, Fang X. Difunctional pluronic copolymer micelles for paclitaxel delivery: Synergistic effect of folate-mediated targeting and pluronic-mediated overcoming multidrug resistance in tumor cell lines. Int J Pharm 2007;337(1-2):63-73. [PubMed: 17289311]

40. Song H, He R, Wang K, Ruan J, Bao C, Li N, et al. Anti-Hif-1Alpha antibody-conjugated pluronic triblock copolymers encapsulated with paclitaxel for tumor targeting therapy. Biomaterials 2009;31 (8):2302-12. [PubMed: 20004970] 
41. Lee SC, Kim C, Kwon IC, Chung H, Jeong SY. Polymeric micelles of poly(2-ethyl-2-oxazoline)block-poly( $\varepsilon$-caprolactone) copolymer as a carrier for paclitaxel. J Control Release 2003;89(3):43746. [PubMed: 12737846]

42. Szebeni J, Baranyi L, Savay S, Milosevits J, Bodo M, Bunger R, et al. The interaction of liposomes with the complement system: In vitro and in vivo assays. Methods Enzymol 2003;373:136-54. [PubMed: 14714402]

43. Waschinski CJ, Herdes V, Schueler F, Tiller JC. Influence of satellite groups on telechelic antimicrobial functions of polyoxazolines. Macromol Biosci 2005;5(2):149-56. [PubMed: 15719430]

44. Taubmann C, Luxenhofer R, Cesana S, Jordan R. First aldehyde-functionalized poly(2-oxazoline)s for chemoselective ligation. Macromol Biosci 2005;5(7):603-12. [PubMed: 15997438]

45. Cesana S, Auernheimer J, Jordan R, Kessler H, Nuyken O. First poly (2-oxazoline) s with pendant amino groups. Macromol Chem Phys 2006;207(2):183-92.

46. Nuyken O, Maier G, Groß A, Fischer H. Systematic investigations on the reactivity of oxazolinium salts. Macromol Chem Phys 1996;197(1):83-95.

47. Luxenhofer R, López-García M, Frank A, Kessler H, Jordan R. First poly (2-oxazoline)-peptide conjugate for targeted radionuclide cancer therapy. PMSE Prepr 2006;95:283-4.

48. Cesana S, Kurek A, Baur MA, Auernheimer J, Nuyken O. Polymer-Bound thiol groups on poly (2oxazoline)s. Macromol Rapid Comm 2007;28(5):608-15. 


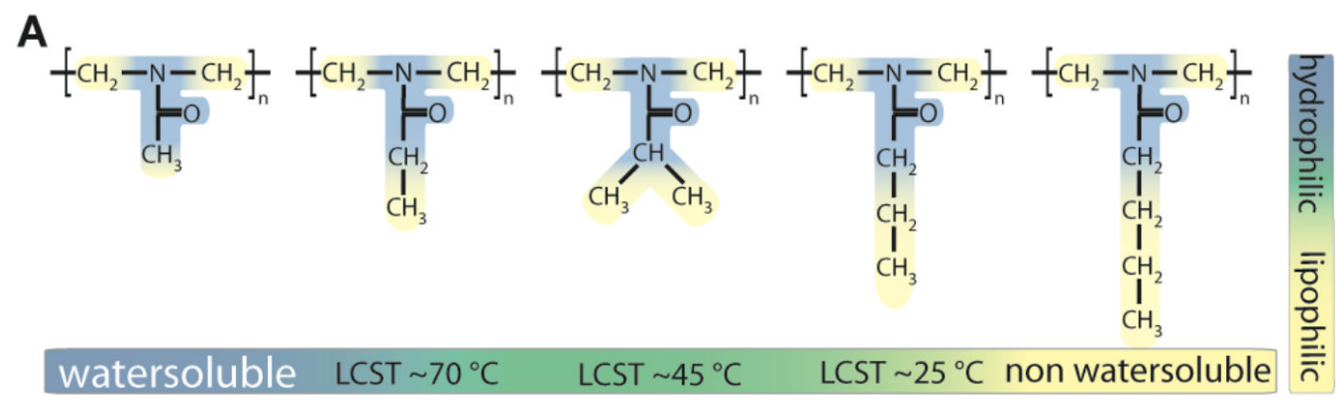

B
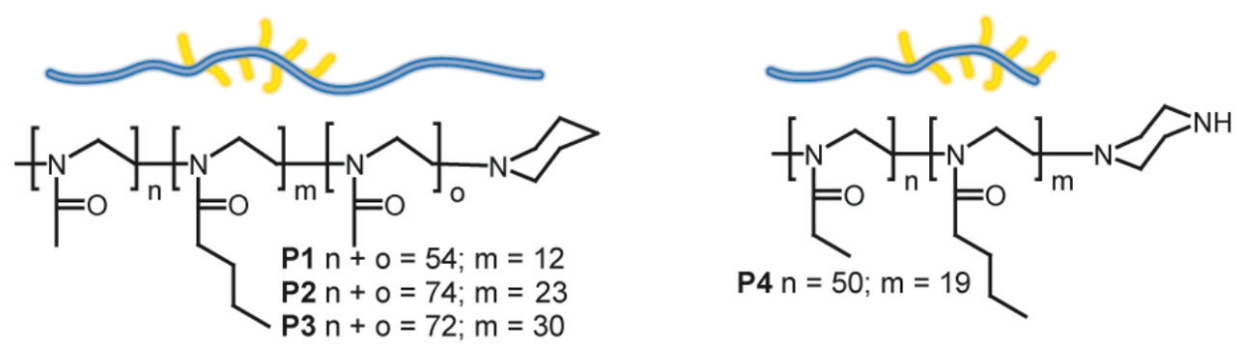

Fig. 1.

A) The homologue series of poly(2-alkyl-2-oxazoline)s that share the polar amide motif with decreasing water solubility as the 2-alkyl side chain length increases. POx with intermediate side chain length display a temperature dependant solubility (lower critical solution temperature (LCST). B) Polymer structures of polymers P1-P4 used in the present study. 


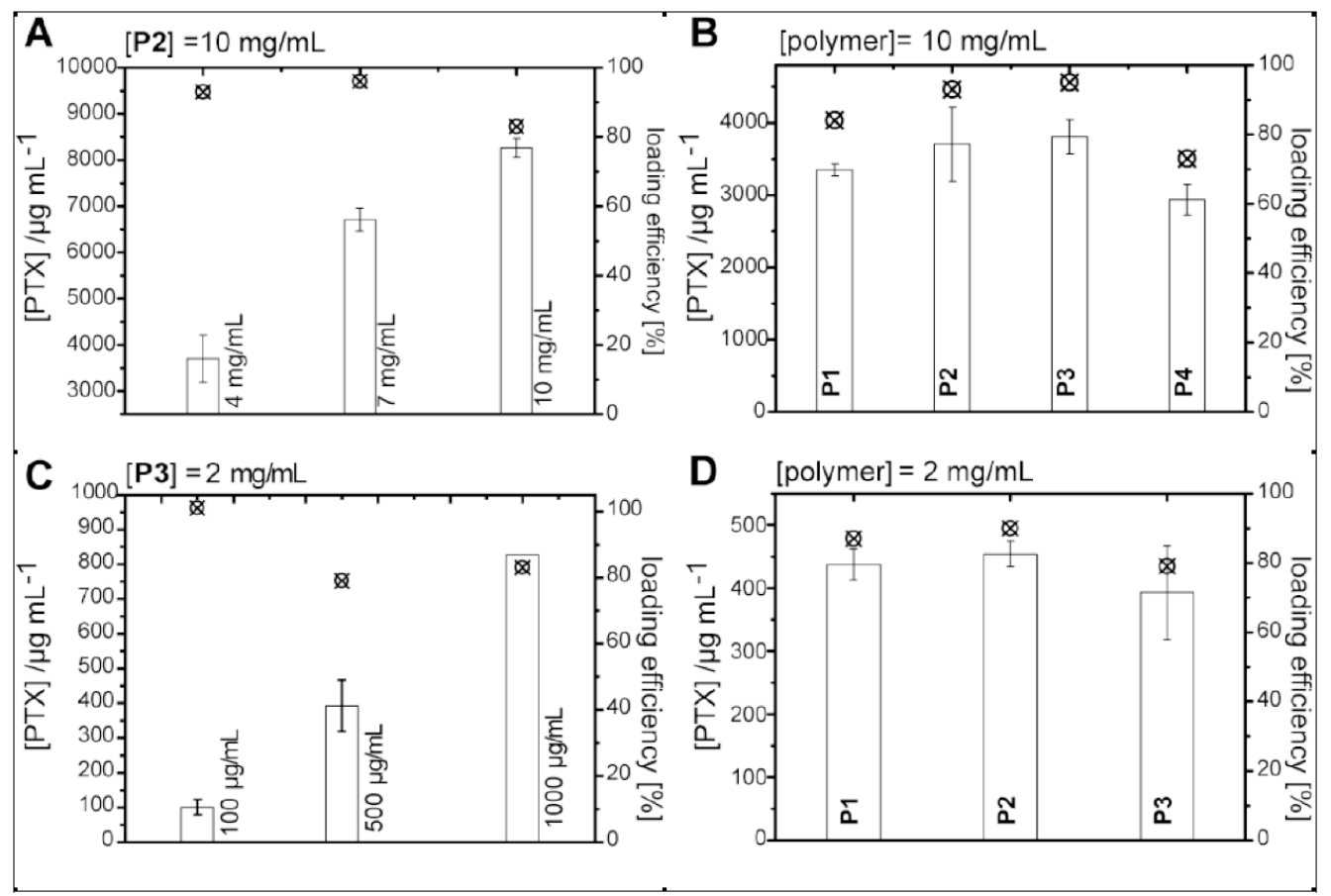

Fig. 2.

Solubilization of PTX with amphiphilic POx block copolymers using the film method. A-D) Solution concentration of PTX (bars) and loading efficiency (crossed circles) using different polymers and targeted PTX concentrations: A) P2 $(10 \mathrm{mg} / \mathrm{mL})$ and $4 \mathrm{mg} / \mathrm{mL}, 7 \mathrm{mg} / \mathrm{mL}$ and $10 \mathrm{mg} / \mathrm{mL}$ PTX. B) P1-P4 (10 mg/mL) and $4 \mathrm{mg} / \mathrm{mL}$ PTX; C) P3 (2 mg/mL) and $100 \mu \mathrm{g} / \mathrm{mL}$, $500 \mu \mathrm{g} / \mathrm{mL}$ and $1 \mathrm{mg} / \mathrm{mL}$ PTX; D) P1-P3 $(2 \mathrm{mg} / \mathrm{mL})$ and $500 \mu \mathrm{g} / \mathrm{mL}$ PTX. Data is presented as means $(\mathrm{n}=3$; except for C: $1 \mathrm{mg} / \mathrm{mL}$ PTX $\mathrm{n}=1$, and B: P4 $\mathrm{n}=2) \pm$ SEM. 
A

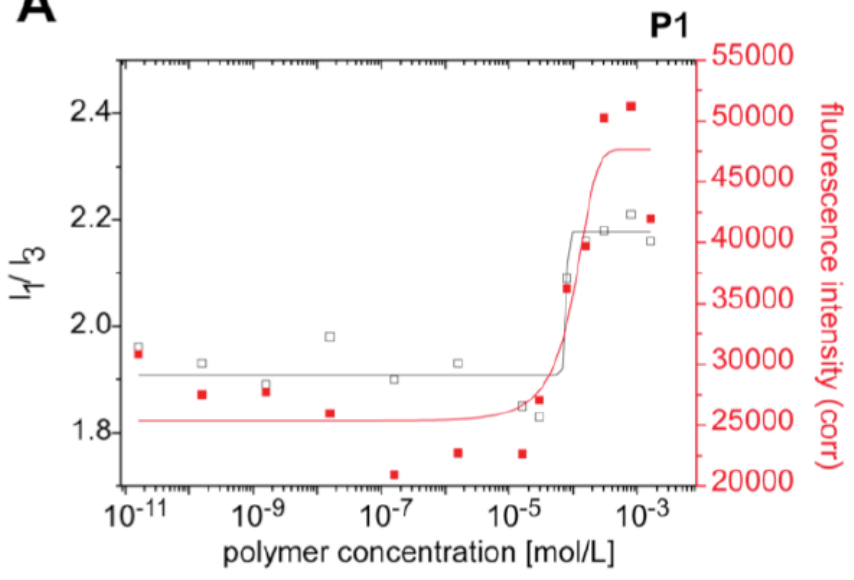

C

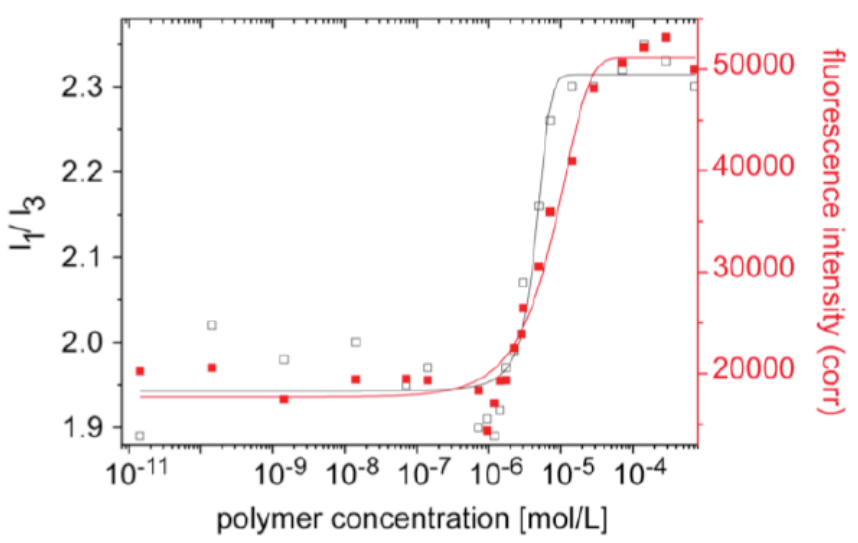

B

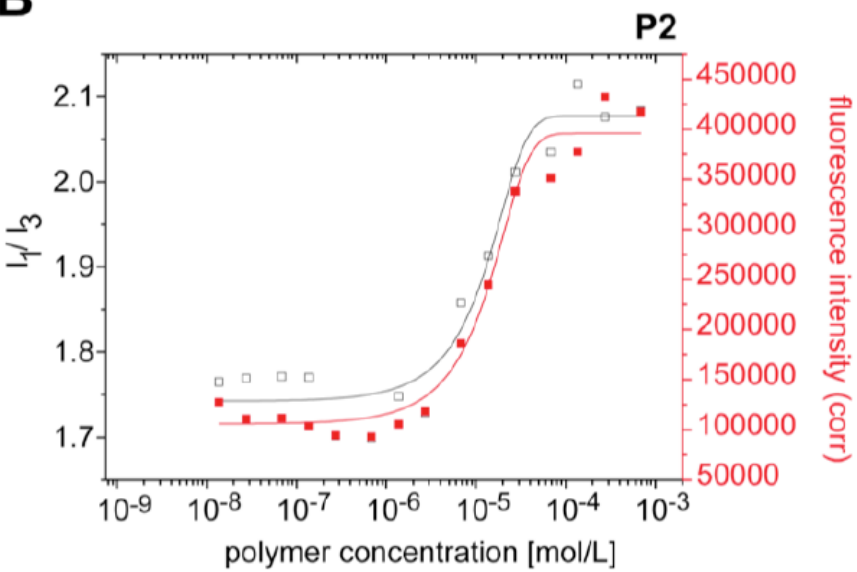

D
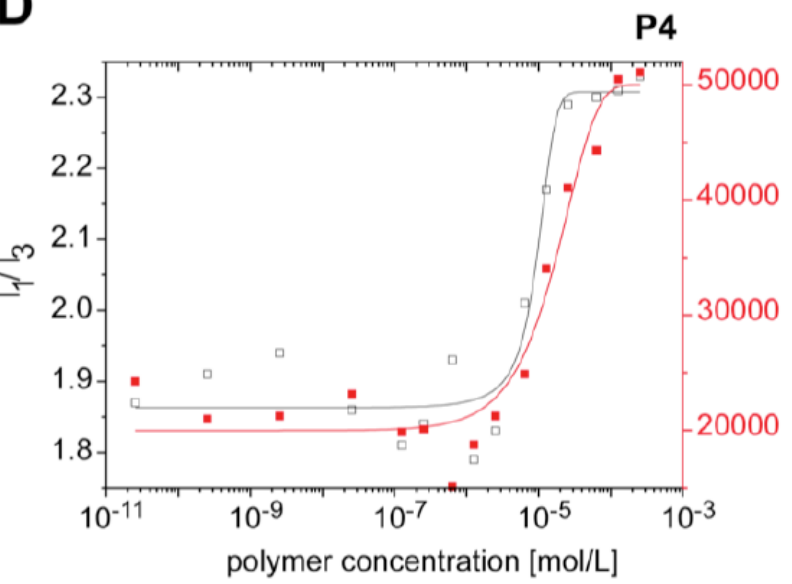

Fig. 3.

Fluorescence intensity and $\mathrm{I}_{1} / \mathrm{I}_{3}$ ratios of pyrene solutions $\left(5 \times 10^{-7} \mathrm{M}\right.$ in phosphate buffered saline (PBS)) in dependence of concentration of P1-P4 at $25^{\circ} \mathrm{C}$. 
A

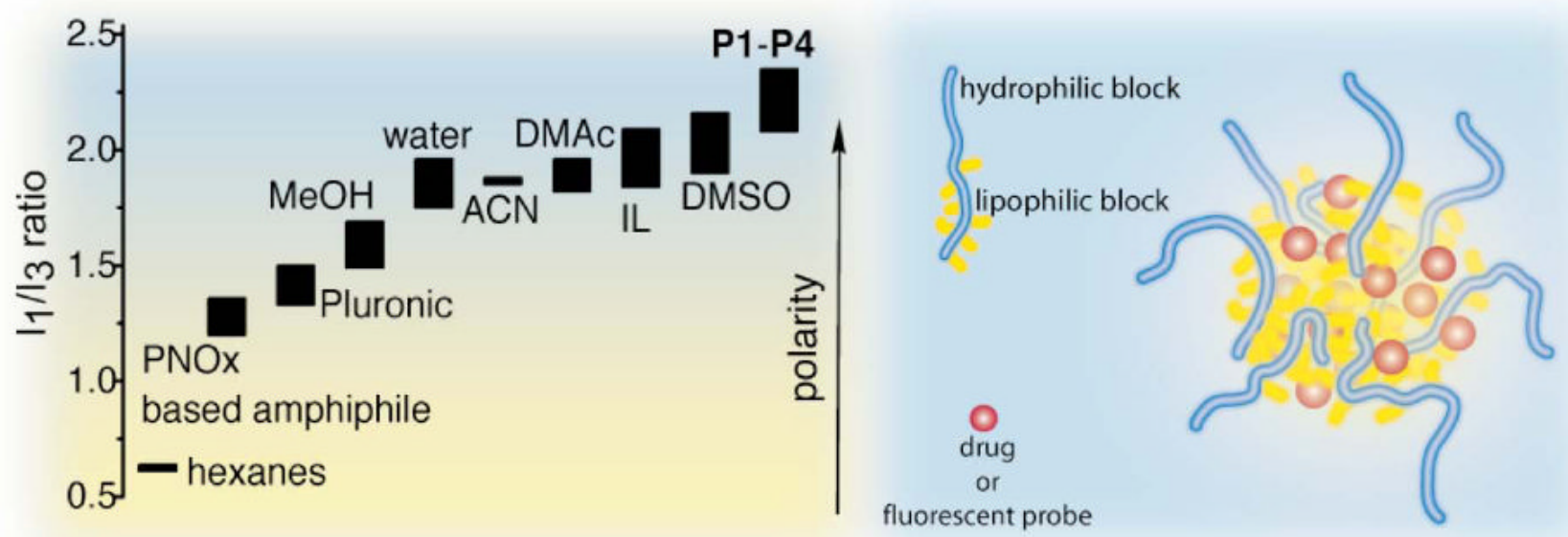

Fig. 4.

A) $\mathrm{I}_{1} / \mathrm{I}_{3}$ ratios (details in Table $\mathrm{S} 1$ ) of pyrene fluorescence spectra in various solvents, ionic liquids (IL) and aqueous solutions of polymer micelles. B) Schematic representation of drug loaded PBuOx-based micelles. 

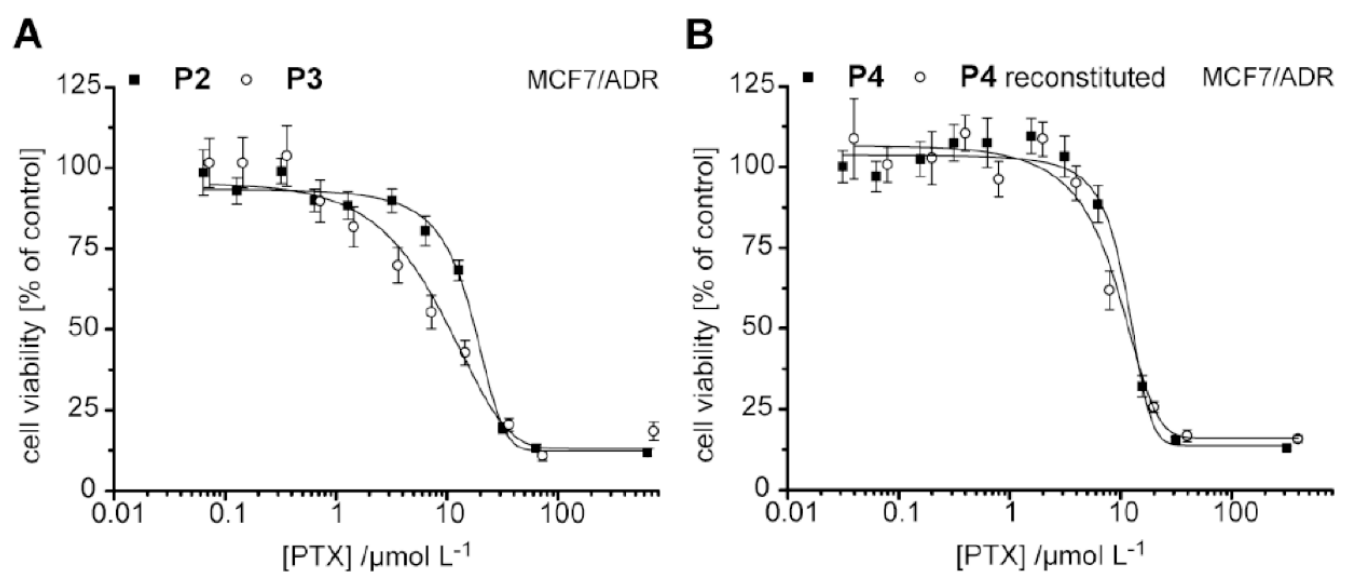

Fig. 5.

PTX dose dependent viability of human multi-drug resistant MCF7/ADR cells. A) Comparison of P2 and P3 formulated PTX shows no difference for the cell viability in dependence of the carrier material after $24 \mathrm{~h}$ of incubation. B) Exemplified for P4, no change in PTX activity is observed after freeze-drying and reconstitution in deionized water. Data is presented as means $(n=3) \pm$ SEM. 


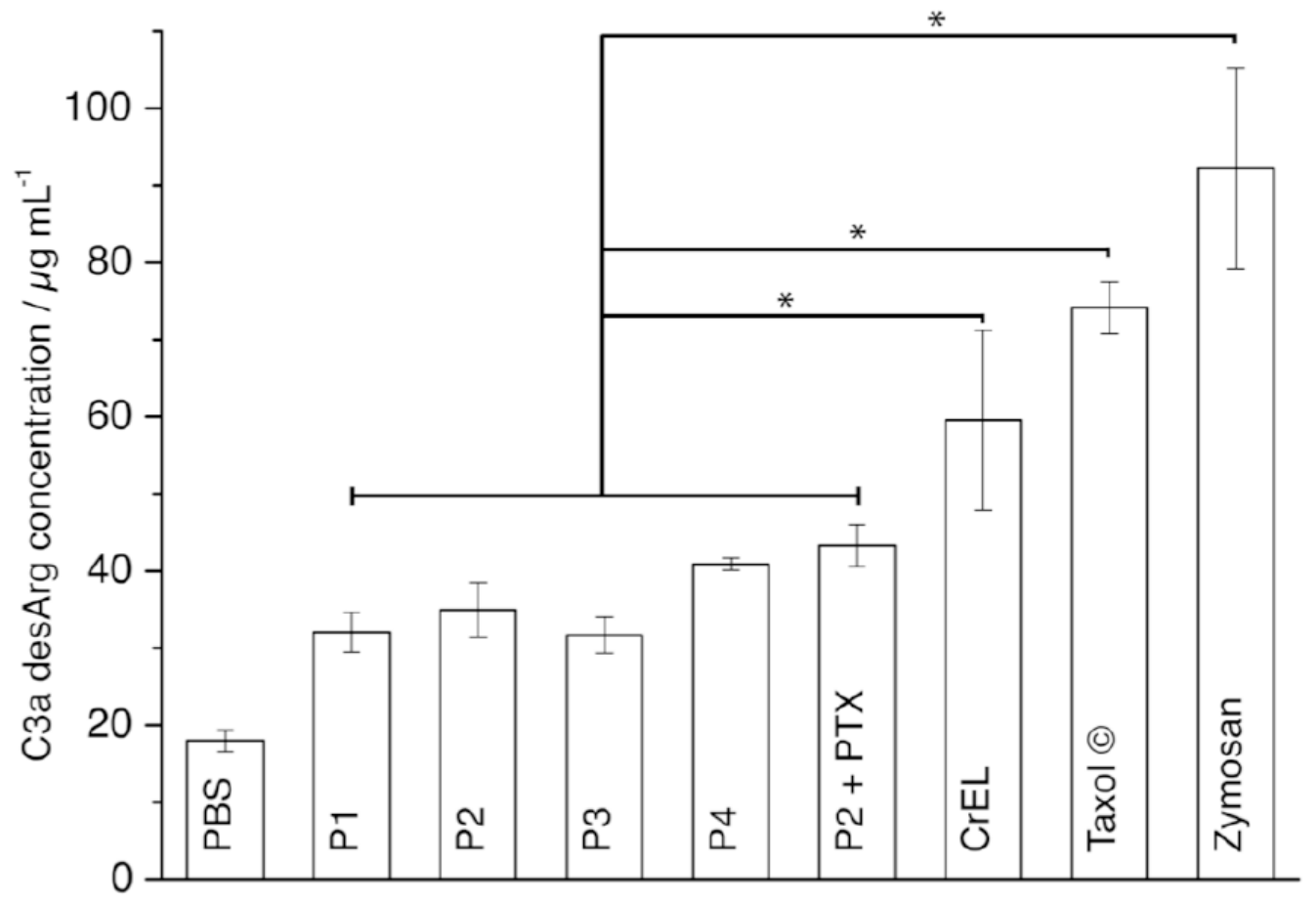

Fig. 6.

Activation of the $\mathrm{C} 3 \mathrm{a}$ complement fraction. Concentrations of C3a-desArg were measured through the ELISA technique. All the poly(2-oxazoline)s, with or without PTX, displayed significantly lower concentrations of C3a-desArg with reference to CrEL alone or with PTX. PBS and Zymosan were used as negative and positive controls respectively. Concentrations are presented as mean $(\mathrm{n}=6) \pm$ S.D.* $\mathrm{p}<0.05$ using Student's $t$-test. 
A

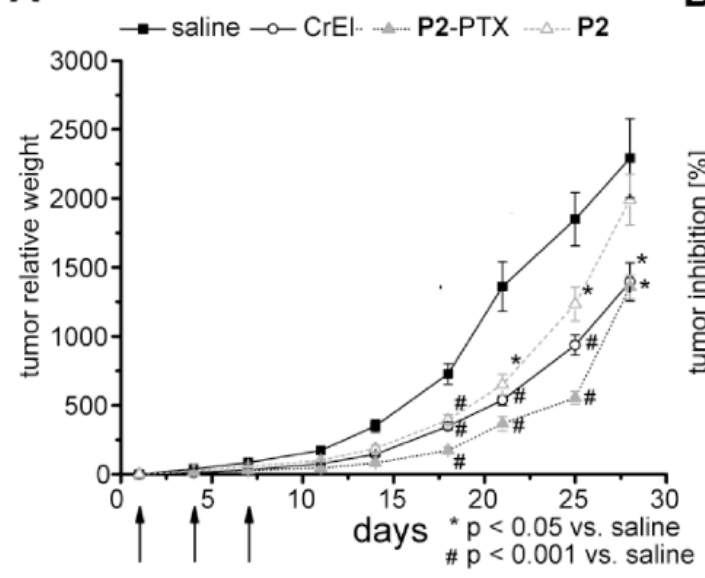

B

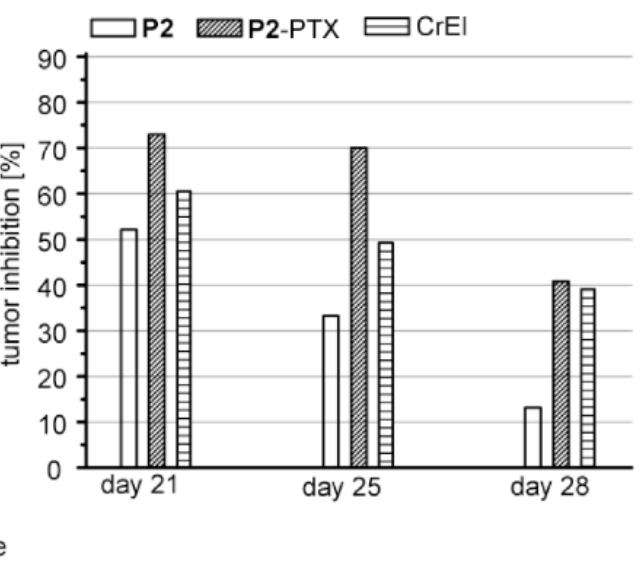

Fig. 7.

Comparison of in vivo tumor growth inhibition in tumor bearing mice. A) Relative tumor weights of subcutaneous Lewis Lung carcinoma tumors in C57/B1/6 mice comparing negative control (saline), treatment with POx solubilized PTX (P2-PTX) and commercial product $(\mathrm{CrEL})$ at the same PTX doses $(10 \mathrm{mg} / \mathrm{kg})$. Arrows indicate times of injection. Data represented as means $\pm \operatorname{SEM}(\mathrm{n}=5)$. B) Calculated tumor inhibition in treatment groups of P2-PTX and CrEL at days after first appearance of tumors. 
